\title{
Asymmetric Polymerization of Diphenyl-3-pyridylmethyl Methacrylate Leading to Optically Active Polymer with Helical Conformation and Chiral Recognition Ability of the Polymer
}

\author{
Tamaki NaKano, Kyoichi Taniguchi, and Yoshio OKamoto \\ Department of Applied Chemistry, School of Engineering, Nagoya University, \\ Chikusa-ku, Nagoya 464-01, Japan
}

(Received December 19, 1996)

\begin{abstract}
Diphenyl-3-pyridylmethyl methacrylate was synthesized and polymerized using the complexes of $N, N^{\prime}$ diphenylethylenediamine monolithium amide with $(+)$-1-(2-pyrrolidinylmethyl)pyrrolidine, (+)-2,3-dimethoxy-1,4-bis(dimethylamino)butane, and (-)-sparteine in toluene at $-78^{\circ} \mathrm{C}$ (helix-sense-selective polymerization). The obtained polymers were highly isotactic and exhibited large dextrorotation based on helical conformation with excess single-handed helicity. Free radical polymerization with (iso-PrOCOO) ${ }_{2}$ in toluene at $40^{\circ} \mathrm{C}$ also gave an isotactic polymer $(\mathrm{mm} \sim 74 \%$ ). The optically active polymer exhibited chiral recognition ability toward several racemic compounds including hexahelicene, trans-stilbene oxide, and binaphthyl derivatives when adsorbed on macro porous silica gel and used as a stationary phase for high-performance liquid chromatography (HPLC).
\end{abstract}

KEY WORDS Diphenyl-3-pyridylmethyl Methacrylate / Triphenylmethyl Methacrylate / Helix / Anionic Polymerization / Free Radical Polymerization / Chiral Recognition /

Bulky methacrylates such as triphenylmethyl ester (TrMA) give highly isotactic, single-handed helical polymers by anionic polymerization using optically active initiators (helix-sense-selective polymerization). ${ }^{1,2}$ The optically active, helical polymethacrylates exhibit excellent chiral recognition ability toward a wide range of racemic compounds when used as a stationary phase for high-performance liquid chromatography (HPLC). ${ }^{3,4}$ However, the poly(TrMA) stationary phase has a drawback that the ester linkage is readily solvolyzed by methanol, a good solvent for HPLC, and the helical structure is lost. In the search for more durable helical polymethacrylates, we have designed several monomers containing 2-pyridyl group in the tertiary ester structure, which include diphenyl-2-pyridylmethyl (D2PyMA), ${ }^{5}$ phenyl-2-pyridyl- $o$ - and - $m$-tolylmethyl, ${ }^{6,7}$ phenyl[bis(2pyridyl) $]$ methyl, ${ }^{8}$ and 1-(2-pyridyl)dibenzosuberyl ${ }^{9}$ esters, in addition to diphenyl-4-pyridylmethyl ${ }^{5 a}$ ester.

In this study, we synthesized diphenyl-3-pyridylmethyl methacrylate (D3PyMA) in order to examine the effects of 3-pyridyl group on durability of the monomer against methanolysis, polymerization stereochemistry, stability of polymer conformation, and chiral recognition ability of the polymer.

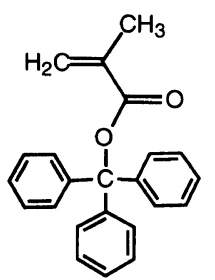

TrMA
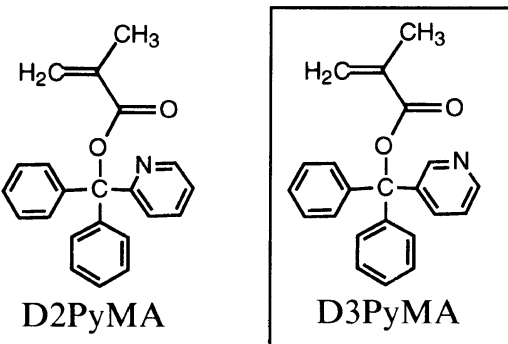

\section{EXPERIMENTAL}

\section{Material}

Diphenyl-3-pyridylmethanol was synthesized by a literature method ${ }^{10}$ with modifications. 3-Bromopyridine (Tokyo Chemical Industry, Co., Ltd.) was dried over $\mathrm{CaH}_{2}$ and distilled under reduced pressure immediately before use. A solution of 3-bromopyridine (126 g, 0.80 mol) in $300 \mathrm{ml}$ of ether was added dropwise to a solution of butyllithium $(0.76 \mathrm{~mol})$ in $900 \mathrm{ml}$ of ether cooled at $-55^{\circ} \mathrm{C}$ with stirring under dry nitrogen atmosphere to form 3-1ithiopyridine. After stirring for $90 \mathrm{~min}$, a solution of benzophenone $(160 \mathrm{~g}, 0.88 \mathrm{~mol})$ in $310 \mathrm{ml}$ of ether was added and the mixture was allowed to warm slowly to room temperature. The reaction was quenched by adding $500 \mathrm{ml}$ of water. The product was extracted using $\mathrm{CHCl}_{3}$ and recrystallized from ethyl acetate to give $98 \mathrm{~g}(47 \%)$ of diphenyl-3-pyridylmethanol. mp $123.0-124.5^{\circ} \mathrm{C} .{ }^{1} \mathrm{H}$ NMR $\left(200 \mathrm{MHz}, \mathrm{CDCl}_{3}\right.$, $\left.\mathrm{Me}_{4} \mathrm{Si}\right) \delta 3.50(\mathrm{~s}, 1 \mathrm{H},-\mathrm{OH}), 7.19-8.49 \mathrm{ppm}(\mathrm{m}, 14 \mathrm{H}$, aromatic).

D3PyMA was prepared as follows. A solution of the alcohol $(30 \mathrm{~g}, 0.12 \mathrm{~mol})$ in $70 \mathrm{ml}$ of tetrahydrofuran (THF) was added to $14 \mathrm{~g}(0.35 \mathrm{~mol})$ of sodium hydride in $30 \mathrm{ml}$ of THF at room temperature and the obtained suspension was refluxed with stirring for $15 \mathrm{~h}$ under nitrogen to form sodium alkoxide. The reaction mixture was then cooled at $0^{\circ} \mathrm{C}$ and methacryloyl chloride $(15 \mathrm{~g}$, $0.14 \mathrm{~mol}$ ) was added dropwise in a $1-\mathrm{h}$ period with stirring. The reaction mixture was stirred at ambient temperature for additional $16 \mathrm{~h}$. After removing THF by evaporation, aq. $\mathrm{Na}_{2} \mathrm{CO}_{3}$ was added to the residue and the product was extracted by ether. The crude product was purified first by silica gel column chromatography with hexane-ether $(1: 1, \mathrm{v} / \mathrm{v})$ as eluent and then by recrystallization once from ether and once from benzenehexane $(1: 1, \mathrm{v} / \mathrm{v})$ to give pure D3PyMA. Yield $4.0 \mathrm{~g}$ (11\%). mp 88.0-90.0 $0^{\circ}$. ${ }^{1} \mathrm{H}$ NMR $\left(500 \mathrm{MHz}, \mathrm{CDCl}_{3}\right.$, $\left.\mathrm{Me}_{4} \mathrm{Si}\right) \delta 1.99\left(\mathrm{~s}, 3 \mathrm{H}, \alpha-\mathrm{CH}_{3}\right), 5.66$ and $6.26(\mathrm{~m}$, $2 \mathrm{H}$, vinyl $\mathrm{H}), 7.23-8.65 \mathrm{ppm}(\mathrm{m}, 14 \mathrm{H}$, aromatic). IR (KBr) $1719 \mathrm{~cm}^{-1}(\mathrm{C}=\mathrm{O}), 1638 \mathrm{~cm}^{-1}(\mathrm{C}=\mathrm{C})$. Anal. Calcd for $\mathrm{C}_{22} \mathrm{H}_{19} \mathrm{NO}_{2}$ : C, $80.21 \%$; H, 5.81\%; N, 4.25\%. Found: C, $80.22 \%$; H, $5.80 \%$; N, $4.16 \%$. 


\section{Polymerization}

The procedure of polymerization is the same as that reported for $\operatorname{TrMA}^{2 \mathrm{~b}}$ except that $N, N^{\prime}$-diphenylethylenediamine monolithium amide was used as initiator instead of 9-fluorenyllithium. Part of the obtained polymer was converted to methyl ester (PMMA) by solvolysis of the ester group using $\mathrm{MeOH}$ containing $\mathrm{HCl}$ followed by methylation using $\mathrm{CH}_{2} \mathrm{~N}_{2} \cdot{ }^{2 b}$ The details of reaction conditions are found in Table II. Tacticity of the polymers was determined by ${ }^{1} \mathrm{H}$ NMR analysis of PMMA derived from the original polymer. Degree of polymerization (DP) of the products was determined by GPC using a calibration curve based on standard polystyrene samples.

\section{Preparation of Chiral HPLC Column}

The optically active polymer (run 1 in Table II) $(0.75 \mathrm{~g})$ dissolved in $12 \mathrm{ml}$ of $\mathrm{CHCl}_{3}$ was added to $3 \mathrm{~g}$ of silica gel (Daisogel, particle size $7 \mathrm{~mm}$, pore size $1000 \AA$ ) silanized with 3-aminopropyltriethoxysilane and the polymer-coated gel was dried under reduced pressure. The silica gel was packed in a stainless steel column $[25 \times 0.46$ (i.d.) $\mathrm{cm}]$ by a slurry method. The theoretical plate number of the column and the dead volume measured for acetone were 2450 and $3.45 \mathrm{ml}$, respectively, when a mixture of hexane and 2-propanol (95:5, $\mathrm{v} / \mathrm{v}$ ) was used as eluent at a flow rate of $0.5 \mathrm{ml} \mathrm{min}^{-1}$. HPLC resolution experiment was performed using a mixture of hexane and 2-propanol or a mixture of methanol and water at a flow rate of $0.5 \mathrm{ml} \mathrm{min}^{-1}$ at ambient temperature with UV $(254 \mathrm{~nm})$ and polarimetric $\left(\alpha_{\mathrm{Hg}}\right)$ detections.

\section{Measurement}

${ }^{1} \mathrm{H}$ NMR was taken on a Varian VXR-500 spectrometer $\left(500 \mathrm{MHz}\right.$ for ${ }^{1} \mathrm{H}$ measurement) or a Varian Gemini-200 spectrometer $\left(200 \mathrm{MHz}\right.$ for ${ }^{1} \mathrm{H}$ measurement). Optical rotation was measured with a JASCO DIP-181 polarimeter. Circular dichroism (CD) spectra were taken using a JASCO J-720L spectrometer. GPC of PMMA was performed at $30^{\circ} \mathrm{C}$ with a TOSOH HLC802A chromatograph equipped with a TSK$\mathrm{G} 3000 \mathrm{H} 8$ and a G5000H6 columns connected in series (eluent $\mathrm{CHCl}_{3}$; flow rate, $1.2 \mathrm{ml} \mathrm{min}^{-1}$ ). GPC of poly(D3PyMA) was performed with a JASCO PU-980 chromatographic pump equipped with a TOSOH TSKG4000H8 and a Shodex K802.5 GPC columns connected in series using a JASCO $875 \mathrm{UV}$ UV detector $(254 \mathrm{~nm})$ and a Shodex OR-1 polarimetric detector $\left(\alpha_{780}\right)$ (eluent $\mathrm{CHCl}_{3}$; flow rate, $0.5 \mathrm{ml} \mathrm{min}{ }^{-1}$ ). HPLC resolution was carried out using a JASCO 880-PU chromatographic pump, a $875 \mathrm{UV}$ UV detector $(254 \mathrm{~nm})$, and a JASCO DIP-181C polarimetric detector $\left(\alpha_{\mathrm{Hg}}\right)$.

\section{RESULTS AND DISCUSSION}

\section{Methanolysis of D3PyMA}

Durability of ester linkage of D3PyMA against solvolysis was evaluated by determining methanolysis rate in a mixture $\mathrm{CDCl}_{3}$ and $\mathrm{CD}_{3} \mathrm{OD}$ at $35^{\circ} \mathrm{C}$. The reaction was directly monitored by means of ${ }^{1} \mathrm{H}$ NMR spectroscopy. The rate constant was obtained as a slope value of first-order plot of the obtained data and the
Table I. Methanolysis of bulky methacrylates in $\mathrm{CDCl}_{3}-\mathrm{CD}_{3} \mathrm{OD}(1: 1, \mathrm{v} / \mathrm{v})$ at $35^{\circ} \mathrm{C}^{\mathrm{a}}$

\begin{tabular}{|c|c|c|}
\hline \multirow{2}{*}{ Monomer } & $k^{\mathrm{b}}$ & Half-life period \\
\hline & $h^{-1}$ & $\min$ \\
\hline D3PyMA & 0.0291 & 1430 \\
\hline D2PyMA & $0.0256^{\mathrm{c}}$ & $1620^{\mathrm{c}}$ \\
\hline TrMA & $2.86^{\mathrm{c}}$ & $14.5^{c}$ \\
\hline
\end{tabular}

${ }^{\mathrm{a}}$ Concentration, $0.39-0.40 \mathrm{moll}^{-1}$. $\quad{ }^{\mathrm{b}}$ Pseudo first-order rate constant. ${ }^{\mathrm{c}}$ Data from ref $3 \mathrm{~b}$.

half-life period was calculated based on the rate constant. The results are shown in Table I along with the data for TrMA and D2PyMA ${ }^{3 b}$ for comparison. D3PyMA has a longer half-life period than TrMA, suggesting that the electron-withdrawing character of 3-pyridyl group destabilize the triaryl cation which is considered to be involved in the methanolysis reaction. Based on these results, the ester linkage in poly(D3PyMA) is expected to be more resistant against methanolysis than that in poly(TrMA). However, the half-life period of D3PyMA is slightly shorter than that of D2PyMA. The electron-withdrawing effect of $\mathrm{N}$ atom in pyridyl ring may be slightly greater when it is at 2-position than at 3-position.

\section{Asymmetric Anionic Polymerization and Free-Radical Polymerization}

The conditions and results of polymerization are summarized in Table II. Asymmetric anionic polymerization was carried out in toluene at $-78^{\circ} \mathrm{C}$ using the complexes of $N, N^{\prime}$-diphenylethylenediamine monolithium amide (DPEDA-Li) with $(+)$-1-(2-pyrrolidinylmethyl)pyrrolidine (PMP), (+)-2,3-dimethoxy-1,4-bis(dimethylamino)butane (DDB), and (-)-sparteine (Sp) (runs 1-5). The polymers obtained using PMP- and

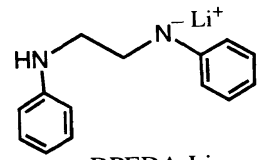

DPEDA-Li<smiles>CO[C@@H](CN(C)C)[C@@H](CN(C)C)OC</smiles>

(+)-DDB

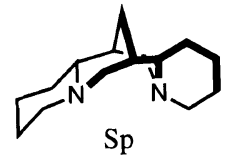

$\mathrm{Sp}$

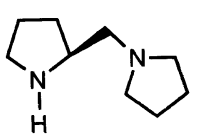

(+)-PMP
DDB-complexes were highly isotactic and showed large dextrorotation, suggesting that these polymers have helical conformation with excess single-handed helicity (runs $1-3$ and 5). The polymer of run 2 also showed intense CD absorptions $\left([\theta]_{232 \mathrm{~nm}} 39000\right)$. However, the rotation values are smaller than those for one-handed helical poly(TrMA) and poly(D2PyMA) obtained using PMP as a chiral ligand, suggesting that the degree of helical sense excess of the poly(D3PyMA)s obtained in the present study is smaller than those of the $\operatorname{poly}(\operatorname{TrMA})^{2}\left([\alpha]_{365} \quad 1200-1500^{\circ}\right)$ and poly(D2PyMA $)^{5 b, c}\left(1300-1700^{\circ}\right)$. We have already pointed out that stereocontrol of D2PyMA polymerization is more difficult than that of TrMA polymerization probably because the coordination of 2-pyridyl group of D2PyMA 


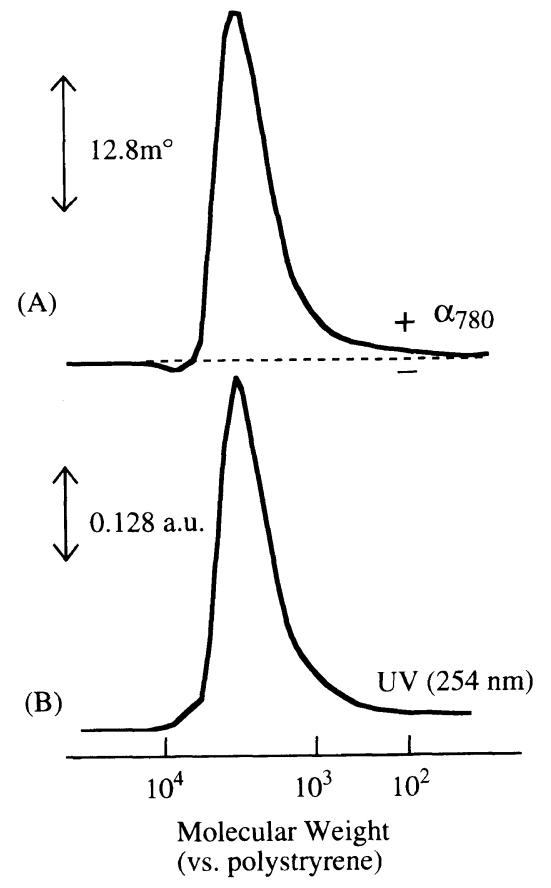

Figure 1. GPC curves of poly(D3PyMA) (run 2 in Table II) obtained by polarimetric $\left(\alpha_{780}\right)$ (A) and UV $(254 \mathrm{~nm})$ (B) detections.

to $\mathrm{Li}$ cation at the growing center prevents effective coordination of the chiral ligand and one-handed helical poly(D2PyMA) can only be obtained using PMP ligand. ${ }^{5}$ 3-Pyridyl group may have a stronger coordination ability to Li cation than 2-pyridyl group because the polymerization of D3PyMA using PMP results in much lower optical activity than that of poly(D2PyMA) synthesized with the same chiral ligand. The coordination of 3-pyridyl group to Li cation may also be responsible for the result that tacticity and optical activity varied depending on the $[\mathrm{M}] /[\mathrm{I}]$ ratio of reaction in the polymerization using PMP. The polymer obtained with Sp-complex had lower isotacticity and smaller optical activity (run 4). This polymer's helical conformation may be less complete and helical sense excess may be much lower compared with that of the polymers obtained with PMP- and DDB-initiators. The polymerization using DPEDA-Li without a chiral ligand in tetrahydrofuran afforded an almost perfectly isotactic polymer (run 6) and free radical polymerization resulted in an isotactic polymer (run 7). These polymers are considered to be equimolar mixtures of right- and lefthanded helices.

In order to obtain information on the chiral polymer structure, GPC analysis with simultaneous UV and polarimetric detections was performed for the polymer of run 2 (Figure 1). Although this polymer exhibited the largest dextrorotation among the polymers obtained in this study, the chromatogram obtained by polarimetric detection did not completely correspond to the concentration chromatogram (UV) and levorotatory fractions existed in the highest molecular weight region, indicating that the helical sense excess depends on molecular weight and the polymer is not perfectly single-handed.

Intriguing information was obtained by monitoring change of optical activity of asymmetric anionic po-

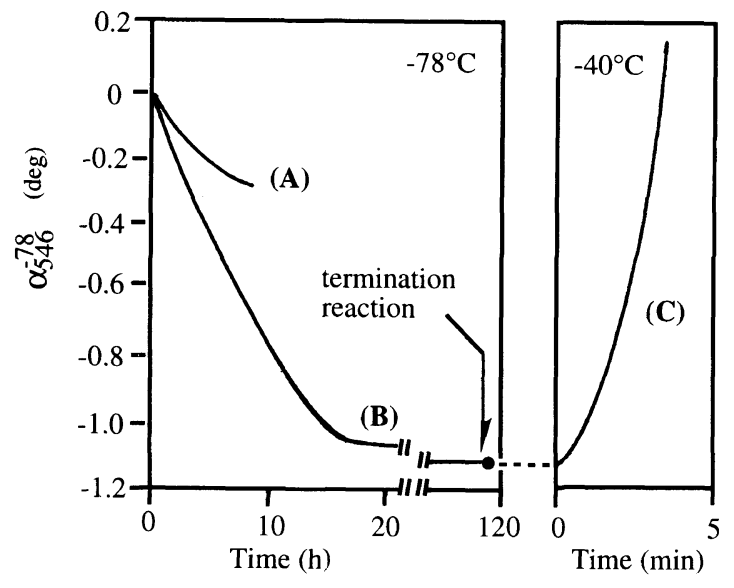

Figure 2. Change in optical activity of polymerization systems of D3PyMA with DDB-DPEDA-Li (A) and PMP-DPEDA-Li (B) in toluene at $-78^{\circ} \mathrm{C}$ and that of the system with PMP at $-40^{\circ} \mathrm{C}$ after termination reaction $(\mathrm{C})$. Conditions: cell length, $1.0 \mathrm{~cm}$; monomer, $0.15 \mathrm{~g}$; toluene, $3 \mathrm{ml}$; [monomer] $/[$ initiator $]=20$.

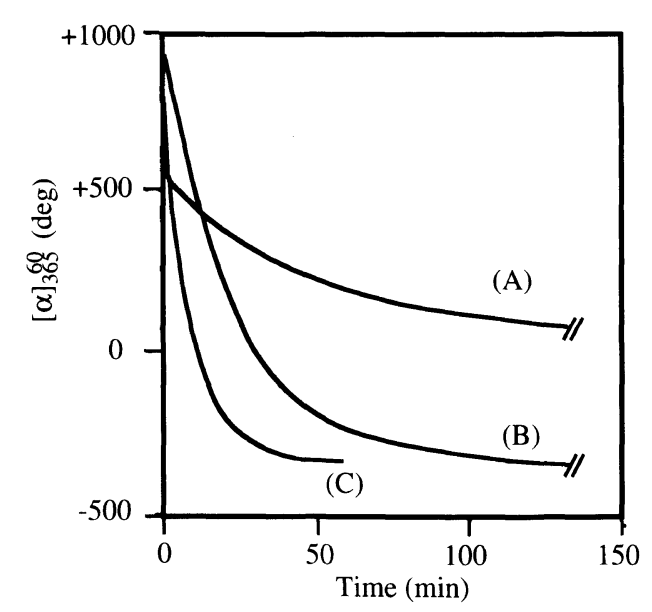

Figure 3. Change in optical activity of poly(D3PyMA) with various DPs in $\mathrm{CHCl}_{3}$ at $60^{\circ} \mathrm{C}$ : DP $=72$ (run 3 in Table II) (A), DP $=40$ (run 2 in Table II) (B), and DP $=32$ (run 1 in Table II) (C). Values of curves (A), (B), and (C) reached $-6^{\circ}$ in $360 \mathrm{~min},-342^{\circ}$ in $190 \mathrm{~min}$, and $-323^{\circ}$ in $60 \mathrm{~min}$, respectively.
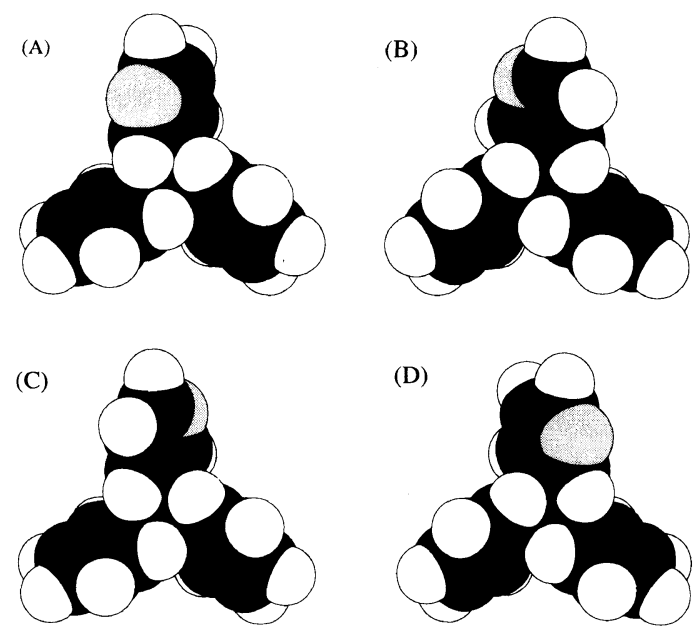

Figure 4. Four interchangeable, isomeric propeller conformations of diphenyl-3-pyridylmethyl group (A) - (D) drawn using Chem3D software package. Atoms in white, darker gray, and lighter gray are hydrogen, carbon, and nitrogen, respectively. 
lymerization systems in a quartz cell (Figure 2 ). The polymerization systems with (+)-DDB and (+)-PMP at $-78^{\circ} \mathrm{C}$ exhibited levorotation with increasing magnitude with reaction time which is opposite in sign to the optical activity of the isolated polymers. Given that the optical activity of the reaction system is based on the formation of helical polymers with excess single-handed helicity, the rate of the change in optical activity should correspond to the rate of polymerization. The polymerization of D3PyMA appears slower than those of TrMA and D2PyMA under similar conditions. ${ }^{2 b, 5 b, c}$

Upon raising the temperature of the reaction system with the PMP-initiator from $-78^{\circ} \mathrm{C}$ to $-40^{\circ} \mathrm{C}$ after the levorotation reached a constant value of $\alpha_{534}^{-78}-1.1^{\circ}$ $\left([\alpha]_{534}^{-78}-230^{\circ}\right.$ assuming a quantitative reaction) and the reaction was terminated by adding a small amount of methanol, optical activity changed in positive direction and the sign changed to positive in $5 \mathrm{~min}$. The reaction mixture upon heating, however, became heterogeneous before the optical activity reaches a constant value. The difference in optical activity between the polymer in the reaction system at $-78^{\circ} \mathrm{C}$ and the isolated polymer may mean some difference in polymer conformation. This point will be discussed later in connection with the change in optical rotation of the isolated polymer at $60^{\circ} \mathrm{C}$.

The isolated polymers exhibited mutarotation in $\mathrm{CHCl}_{3}$ at $60^{\circ} \mathrm{C}$ (Figure 3). The optical activity of the isolated polymers changed in negative direction and reached constant negative values. The mutarotation was faster for a polymer of lower DP and the polymers with $\mathrm{DP}=32$ and 40 showed much larger final levorotations than the polymer with $\mathrm{DP}=78$ and was also observed

Table II. Polymerization of D3PyMA in toluene under anionic and free radical conditions ${ }^{a}$

\begin{tabular}{|c|c|c|c|c|c|c|c|c|c|}
\hline Run & Initiator & {$[\mathrm{M}] /[\mathrm{I}]$} & $\frac{\text { Time }}{h}$ & $\frac{\text { Yield }^{b}}{\%}$ & $\mathrm{DP}^{\mathrm{c}}$ & $M_{w} / M_{n}^{c}$ & $\begin{array}{l}\text { Tacticity }^{\mathrm{d}} \\
(\mathrm{mm} / \mathrm{mr} / \mathrm{rr})\end{array}$ & $\frac{[\alpha]_{365}^{25} \mathrm{e}}{\operatorname{deg}}$ & $\frac{[\alpha]_{\mathrm{D}}^{25 \mathrm{e}}}{\operatorname{deg}}$ \\
\hline 2 & PMP-DPEDA-Li & 20 & 24 & 95 & 40 & 1.07 & $>99 / \sim 0 / \sim 0$ & +918 & +231 \\
\hline 3 & PMP-DPEDA-Li & 50 & 126 & 58 & 78 & 1.45 & $98 / 1 / 1$ & +505 & +107 \\
\hline 4 & Sp-DPEDA-Li & 20 & 163 & 64 & 57 & 1.56 & $89 / 8 / 3$ & +73 & +20 \\
\hline 5 & DDB-DPEDA-Li & 20 & 24 & 70 & 43 & 1.23 & $97 / 2 / 1$ & +280 & +56 \\
\hline $6^{\mathrm{f}}$ & DPEDA-Li & 20 & 24 & 95 & 147 & 1.99 & $>99 / \sim 0 / \sim 0$ & & \\
\hline 7 & $\left(\right.$ iso-PrOCOO) ${ }_{2}$ & 50 & 24 & 60 & 102 & 1.63 & $74 / 19 / 7$ & & \\
\hline
\end{tabular}

${ }^{a}$ Conditions: D3PyMA, $0.5 \mathrm{~g}$ (runs 1, 3, 5-7), $2.0 \mathrm{~g}$ (run 2), $1.0 \mathrm{~g}$ (run 4); solvent $10 \mathrm{ml}$ (runs 1, 3, 5), $40 \mathrm{ml}$ (run 2), $20 \mathrm{ml}$ (run 4), $10 \mathrm{ml}$ (run 6), $8 \mathrm{ml}$ (run 7); temperature, $-78^{\circ} \mathrm{C}$ (runs $1-6$ ), $40^{\circ} \mathrm{C}$ (run 7). ${ }^{b} \mathrm{MeOH}$-insoluble part. ${ }^{\mathrm{c}}$ Determined by GPC (polystyrene standard) of PMMA derived from poly(D3PyMA). ${ }^{\mathrm{d}}$ Determined by ${ }^{1} \mathrm{H}$ NMR analysis of PMMA derived from poly(D3PyMA). ${ }^{\mathrm{e}}$ Measured immediately after dissolving the polymer in $\mathrm{CHCl}_{3}$. ${ }^{\mathrm{f}}$ Polymerization in tetrahydrofuran.

Table III. HPLC Resolution of racemic compounds on (+)-poly(D3PyMA) $)^{\text {a,b }}$

\begin{tabular}{|c|c|c|c|c|c|c|}
\hline Run & Racemic compound & Eluent & $k_{1}^{\prime c}$ & $k_{2}^{\prime}$ & $\alpha$ & $R_{\mathrm{s}}$ \\
\hline 1 & & $\begin{array}{l}\text { Hexane-2-propanol } \\
\quad(98: 2, \mathrm{v} / \mathrm{v})\end{array}$ & $1.04(+)$ & 2.15 & 2.07 & 2.30 \\
\hline 2 & & $\begin{array}{c}\text { Hexane-2-propanol } \\
(9: 1, \mathrm{v} / \mathrm{v})\end{array}$ & $1.37(+)$ & 1.68 & 1.23 & 1.24 \\
\hline 3 & & $\begin{array}{l}\mathrm{MeOH}-\mathrm{H}_{2} \mathrm{O} \\
(9: 1, \mathrm{v} / \mathrm{v})\end{array}$ & $5.18(-)$ & 7.52 & 1.45 & 1.10 \\
\hline 4 & & $\begin{array}{l}\text { Hexane-2-propanol } \\
(98: 2, v / v)\end{array}$ & $0.99(+)$ & 1.16 & 1.18 & 0.73 \\
\hline 5 & & $\begin{array}{c}\mathrm{MeOH}-\mathrm{H}_{2} \mathrm{O} \\
(9: 1, \mathrm{v} / \mathrm{v})\end{array}$ & $4.18(+)$ & 4.82 & 1.15 & Not determined \\
\hline 6 & & $\begin{array}{l}\mathrm{MeOH}-\mathrm{H}_{2} \mathrm{O} \\
(9: 1, \mathrm{v} / \mathrm{v})\end{array}$ & $4.38(+)$ & 4.38 & 1.12 & Not determined \\
\hline
\end{tabular}

${ }^{a} k_{1}^{\prime}=\left(t_{1}-t_{0}\right) / t_{0}, k_{2}^{\prime}=\left(t_{2}-t_{0}\right) / t_{0}$, and $\alpha=k_{2}^{\prime} / k_{1}^{\prime}$ where $t_{1}$ and $t_{2}$ are elution volumes of the antipodes of a racemate and $t_{0}$ is the dead volume of the HPLC columun. ${ }^{\mathrm{b}}$ The poly(D3PyMA) of run 2 in Table II was used. ${ }^{\mathrm{c}}$ Sign of optical rotation of the first-eluted antipode is shown in parenthesis. 
at ambient temperature at a lower rate. Similar change in optical rotation has been observed for optically active poly(D2PyMA) ${ }^{11}$ and poly(cyclohexyldiphenylmethyl methacrylate $)^{12}$ and attributed to helix-helix transition of the main chain leading to the change in helical sense excess. The mutarotation shown in Figure 3 is also probably due to helix-helix transition where the excess helical sense formed through the polymerization process changed into a more thermally stable sense at $60^{\circ} \mathrm{C}$. GPC analysis of the polymers with DP $=72$ and DP $=32$ before and after the mutarotation using $\mathrm{UV}$ and polarimetric detections revealed that the change in rotation took place for the polymer with $\mathrm{DP}=32$ in the entire molecular weight region and for the polymer with $\mathrm{DP}=72$ only for lower molecular weight fractions. This indicates that a polymer having a lower molecular weight more readily undergoes the helix-helix transition.

The mutarotation of the reaction mixture at $-40^{\circ} \mathrm{C}$ described earlier (Figure $2(\mathrm{C})$ ) is considered to be based on some conformational transition that is different from the main-chain helix-helix transition because the change at $-40^{\circ} \mathrm{C}$ was much faster than that at $60^{\circ} \mathrm{C}$. The change at $-40^{\circ} \mathrm{C}$ may be ascribed to a conformational change in side chain triaryl group which has been assumed to be in a propeller shape. ${ }^{1,6 a, 13}$ At least the four isomeric propeller conformations shown in Figure 4 are possible for diphenyl-3-pyridyl group and interchange between the conformations could be responsible for the rather fast mutarotation at $-40^{\circ} \mathrm{C}$.

\section{Chiral Recognition Using Optically Active Poly(D3Py- $M A)$}

The polymer of run 2 in Table II was coated on silica gel and packed into a HPLC column and chiral recognition ability of the polymer was examined by HPLC experiments with a UV $(254 \mathrm{~nm})$ and polarimetric $\left(\alpha_{\mathrm{Hg}}\right)$ detections. The polymer resolved the compounds listed in Table III. trans-Stilbene oxide was completely resolved and antipodes of flavanon and hexahelicene were also well separated (runs 1-3) while other racemic compounds were only partially resolved. The chiral recognition ability appears to be lower than that of one-handed helical poly(TrMA) or poly(D2PyMA). ${ }^{3}$ It is reasonably assumed about the polymer structure that steric hindrance around nitrogen atoms is greater in poly(D2PyMA) than in poly(D3PyMA). This may make the interaction between the nitrogen atoms and the antipodes of racemic compounds play more important roles in resolution on poly(D3PyMA) than on poly(D2PyMA) and may be partially responsible for the difference in chiral recognition ability.

\section{REFERENCES}

1. Y. Okamoto and T. Nakano, Chem. Rev., 94, 349 (1994).

2. (a) Y. Okamoto, K. Suzuki, K. Ohta, K. Hatada, and H. Yuki, J. Am. Chem. Soc., 101, 4763 (1979). (b) T. Nakano, Y. Okamoto, and K. Hatada, J. Am. Chem. Soc., 114, 1318 (1992).

3. (a) Y. Okamoto, S. Honda, I. Okamoto, H. Yuki, S. Murata, S. Noyori, and H. Takaya, J. Am. Chem. Soc., 103, 6971 (1981). (b) Y. Okamoto, H. Mohri, and K. Hatada, Polym. J., 21, 439 (1989).

4. Y. Okamoto and K. Hatada, J. Liq. Chromatogr., 9, 369 (1986).

5. (a) Y. Okamoto, M. Ishikura, K. Hatada, and H. Yuki, Polym. J., 15, 851 (1983). (b) Y. Okamoto, H. Mohri, T. Nakano, and K. Hatada, Chirality, 3, 277 (1991). (c) Y. Okamoto, H. Mohri, and K. Hatada, Chem. Lett., 1879 (1988).

6. (a) Y. Okamoto, E. Yashima, and K. Hatada, J. Polym. Sci., Part C, Polym. Lett., 25, 297 (1987). (b) E. Yashima, Y. Okamoto, and K. Hatada, Macromolecules, 21, 854 (1988).

7. Y. Okamoto, T. Nakano, T. Asakura, H. Mohri, and K. Hatada, J. Polym. Sci., Part A, Polym. Chem., 29, 287 (1991).

8. C. Ren, C. Chen, F. Xi, T. Nakano, and Y. Okamoto, J. Polym. Sci., Part A, Polym. Chem., 31, 2721 (1993).

9. T. Nakano, A. Matsuda, M. Mori, and Y. Okamoto, Polym. J., 28, 330 (1996).

10. H. E. French and K. Sears, J. Am. Chem. Soc., 73, 469 (1951).

11. Y. Okamoto, H. Mohri, T. Nakano, and K. Hatada, J. Am. Chem. Soc., 111, 5952 (1989).

12. Y. Okamoto, T. Nakano, T. Fukuoka, and K. Hatada, Polym. Bull., 26, 258 (1991).

13. (a) Y. Wang, M. Ding, and F. Wang, Makromol. Chem., 192, 1769 (1991). (b) B. Yu, M. Ding, Y. Wang, and F. Wang, J. Polym. Sci., Part A: Polym. Chem., 31, 2681 (1993). 